\title{
Diagnosis | Pancreatitis
}

Based on the severe inflammatory infiltration of the pancreas, we made a diagnosis of acute necrotizing pancreatitis (Fig. 4). We diagnosed the inflammatory infiltration of the gallbladder wall as acute cholecystitis (Fig. 5). Cytologically, we did not see bile, which appears as a golden-green granular pigment in the abdominal fluid; we saw a chronic, non-suppurative, mixed mononuclear response (Fig. 3). This was initially confusing, as the inflammation in both the gallbladder and pancreas was acute and neutrophilic. Therefore, we considered that the peritonitis and peritoneal effusion probably developed secondary to the pancreatitis and leakage of pancreatic enzymes into the abdominal cavity.

Acute pancreatitis or bile leakage caused by perforation of the extrahepatic biliary system may cause an acute chemical injury induced by the sudden release of a large amount of pancreatic enzymes or concentrated bile into the peritoneal cavity. This 'chemical peritonitis' is characterized by peritoneal exudate and sepsis. In humans, acute pancreatitis has been associated with biliary tract disease, especially with gallstone formation and alcohol abuse ${ }^{1}$. Acute cholecystitis and acute pancreatitis are also strongly associated with biliary stones. Despite cases of concurrent acute pancreatitis and cholecystitis in humans ${ }^{2}$, to our knowledge such a condition has not been reported in animals.

In humans, the first sign of pancreatic disease is often bile peritonitis. A sudden release of concentrated bile (often a large amount) into the peritoneal cavity follows abdominal trauma involving either the pancreas or biliary tract. The peritonitis is characterized by mesothelial damage, peritoneal inflammation, and the presence of bile in the peritoneal exudate. The common causes of biliary peritonitis are necrotizing cholecystitis, blunt trauma, and extrahepatic biliary tract obstruction ${ }^{3-5}$. Despite the acute cholecystitis and extensive loss of gallbladder mucosal epithelial cells, it appears the gallbladder never ruptured, as we did not see evidence of bile leakage.

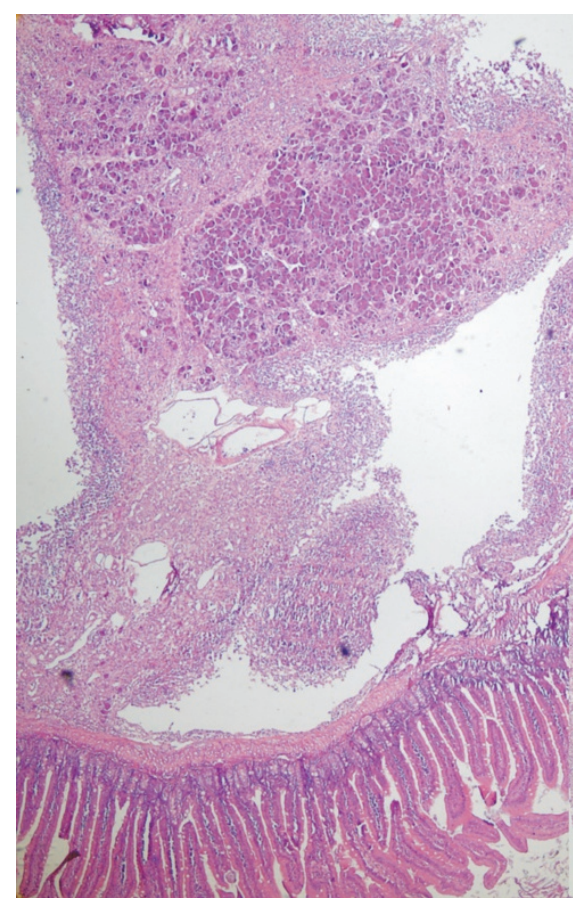

FIGURE 4 | Low-power photomicrograph of the pancreas and part of the duodenum. There is a severe necrosis of the pancreatic lobes and a severe inflammatory infiltrate between the lobules and along the serosal surface of the duodenum.

In this mouse, we encountered an extensive peritoneal effusion associated with acute necrotizing pancreatitis and acute cholecystitis. Blood, pancreatic enzymes, and necrotic tissue accumulation in the peritoneal cavity caused the marked local and systemic inflammatory response ${ }^{6}$. Free hemoglobin from lysed red blood cells in the peritoneal effusion acts as a proinflammatory mediator that enhances the local peritoneal response (by increasing tumor necrosis factor- $\alpha$ production by monocytes) and contributes to both the local and systemic inflammatory responses ${ }^{6}$.

Investigation of biliary abnormalities in 2,500 mice revealed that spontaneous biliary lesions such as cholecystitis and cholangitis are rare and occur predominantly in females ${ }^{7}$. Spontaneous rupture of the biliary tract is also uncommon in humans and animals. However, trauma is a major cause of cholecystitis in $\operatorname{dogs}^{8}$.

The etiology of acute pancreatitis in humans is well-known. As the common bile duct and pancreatic duct are adjacent to one another in the duodenal papilla, pancreatitis secondary to biliary tract obstruction is a common cause; alcohol abuse is another frequent cause. Less often, viral, metabolic, and hereditary diseases cause acute pancreatitis. In $2-10 \%$ of patients, no underlying cause can be identified after initial diagnostic evaluation ${ }^{1,9}$.

Acute pancreatitis may be induced in experimental animals to simulate acute human pancreatitis ${ }^{10}$. This includes obstructing the opossum-common bile-pancreatic duct, administering to mice 12 hourly injections of a supramaximally stimulating dose of caerulein (a decapeptide similar to cholecystokinin that stimulates gastric, biliary, and pancreatic secretion), and feeding young female mice a choline-deficient, ethioninesupplemented diet. In each of these animal models, severe necrotizing pancreatitis is induced. Mild pancreatitis with very little necrosis can be induced by obstructing the rat-common bile-pancreatic duct and by infusing rats with a supramaximally stimulating dose of caerulein.

Group B coxsackieviruses can induce experimental pancreatitis in mice ${ }^{11,12}$. A recent report, along with prior epidemiologic studies, suggests that Helicobacter spp. play a major role in the pathophysiology of cholesterol gallstone formation in mice ${ }^{9}$. We did not evaluate this mouse for Helicobacter infection.

We found no other mouse in our colony with a similar condition, making a nutritional or infectious etiology unlikely. Perforation of the extrahepatic biliary tract-caused by trauma, structural abnormalities, or increased intraluminal pressure following acute pancreatitis or luminal obstructionis rare ${ }^{13-15}$. We did not observe any signs of 


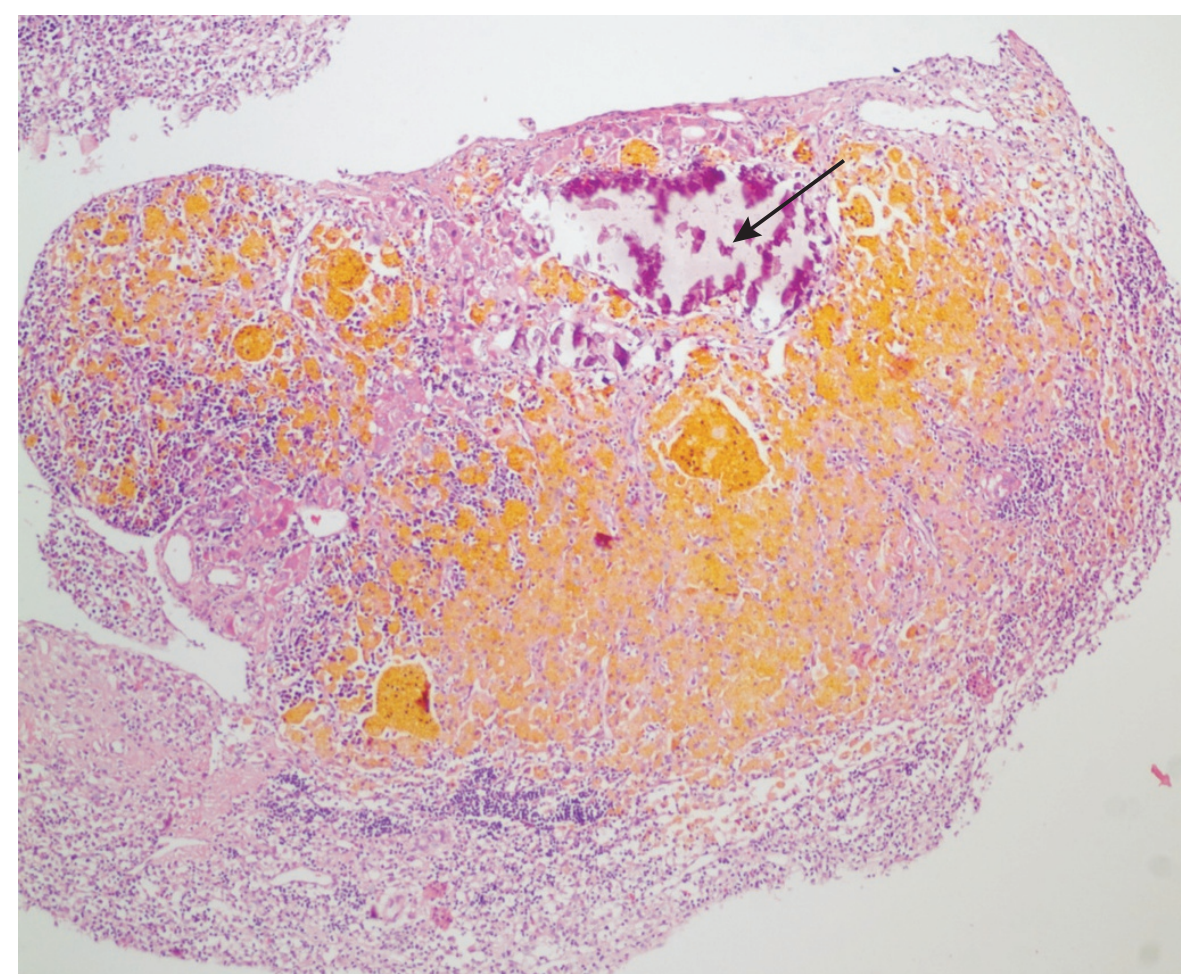

FIGURE 5 | Photomicrograph of the gallbladder wall showing a severe mucosal and mural neutrophilic infiltrate. The yellow-brown pigment is most likely bile and there is microscopic cholelith (arrow) (H \& E stain, $\times 200)$. perforation in this mouse. The pathological findings of extensive peritonitis with severe pancreatitis and acute cholecystitis, in the absence of a cholelith, suggests that biliary obstruction was also not an etiologic factor in this animal. More likely, spontaneous pancreatitis caused an increase in biliary intraluminal pressure and subsequent cholecystitis.

1. Roseano, M. et al. The multidisciplinary of 244 cases. [Italian.] Ann. Ital. Chir. 75(4), 443-453 (2004).

2. Baldwin, M., Eisenman, R.E., Prelipp, A.M. \& Breuer, R.I. Ascaris lumbricoides resulting in tions to "What's Your Diagnosis" in case history/diagnosis format. Submissions should include two to five illustrations to editors@labanimal.com. Selections are made on the basis of relevance and interest to readers. Please refer to the Guide to Authors for information on submission of digital figures. management of acute pancreatitis: a review

LAB ANIMAL welcomes reader contribuor photos. Please email manuscripts
5. Mehler, S.J., Mayhew, P.D., Drobatz, K.J. \& Holt, D.E. Variables associated with outcome in dogs undergoing extrahepatic biliary surgery: 60 cases (1988-2002). Vet. Surg. 33(6), 644-649 (2004).

6. Carrillo, E.H., Gordon, L.E., Richardson, J.D. \& Polk, H.C. Jr. Free hemoglobin enhances tumor necrosis factor-alpha production in isolated human monocytes. J. Trauma 52 (3), 449-452 (2002).

7. Lewis, D.J. Spontaneous lesions of the mouse biliary tract. J. Comp. Pathol. 94(2), 263-271 (1984).

8. Parchman, M.B. \& Flanders, J.A. Extrahepatic biliary tract rupture: evaluation of the relationship between the site of rupture and the cause of rupture in 15 dogs. Cornell Vet. 80(3), 267-272 (1990).

9. van Brummelen, S.E., Venneman, N.G., van Erpecum, K.J. \& VanBerge-Henegouwen, G.P. Acute idiopathic pancreatitis: does it really exist or is it a myth? Scand. J. Gastroenterol. 239, 117-122 (2003).

10. Kaiser, A.M., Saluja, A.K., Sengupta, A., Saluja, M. \& Steer, M.L. Relationship between severity, necrosis, and apoptosis in five models of experimental acute pancreatitis. Am. J. Physiol. 269(5 Pt 1), C1295-C1304 (1995).

11. Tracy, S. et al. Related Group B coxsackievirus myocarditis and pancreatitis: connection between viral virulence phenotypes in mice. J. Med. Virol. 62(1), 70-81 (2000).

12. Smith, R. \& Deibel, R. Coxsackievirus infection in mice. Arch. Intern. Med. 135(2), 238-239 (1975).

13. Arruabarrena, I.M., Goicoechea, X., Coloma, J., Amato, E. \& Vivanco, Y.J. Biliary peritonitis secondary to spontaneous perforation of the distal common bile duct as a complication of acute pancreatitis. [Spanish.] Gastroenterol. Hepatol. 21(7), 370-372 (1998).

14. Broto, J. et al. Bile peritonitis caused by idiopathic perforation of a choledochal cyst. [French.] Arch. Fr. Pediatr. 43(10), 795-797 (1986).

15. Paladugu, R., Rau, A., Schein, M. \& Wise, L. Spontaneous perforation of the hepatic duct in adults. Dig. Surg. 15(5), 417-420 (1998).
4. Geffroy, Y. et al. Massive ascites in pancreatitis. Review apropos of 10 personal cases. [French.] Sem. Hop. 51(14), 927-934 (1975). acute cholecystitis and pancreatitis in the 2121 (1993).

3. Huttunen, R. The proteolytic proenzymes in the peritoneal exudate during acute experimental pancreatitis of the rat. Acta. Chir. Scand. 141(4), 285-288 (1975). 